\title{
El año de la modernización: 1996
}

\author{
Francisco Javier Ibisate
}

\begin{abstract}
Resumen
Cuestionamiento de las definiciones corrientes de modernización, impregnadas de economicismo. El autor recuerda que la modernización va más allá de la economía y propone como parámetro la satisfacción social. La modernización debe ser tan universal como la paz social. Si la satisfacción social no se produce, no se moderniza.
\end{abstract}

\section{1. ¿Qué es modernización?}

El título es una pregunta, acompañada de algunas reflexiones y de una propuesta, ya que se ha puesto de moda hablar de la modernización. La verdad es que no es fácil entender qué nos quieren decir quienes, día a día, aconsejan, piden y reclaman que debemos entrar ya en la vía de la modernización. Hace un año los titulares de nuestros diarios decían que ésta sería la primera tarea de 1995 y, por lo tanto, ya llevamos un año de retraso. También se nos dio a entender que la modernización se aceleraba con la dolarización, la privatización, las maquilas, el impuesto al valor agregado, los aranceles..., pero no todos están de acuerdo.

Una pregunta introductoria es por qué los defensores de la modernización la aplican primordial y casi exclusivamente al Estado, al sector público. Que el Estado deba modernizarse es muy claro, pero los demás, ¿ya estamos modernizados? Parecería que en un mundo donde se globalizan las revoluciones tecnológicas, desde la telemática hasta la biotecnologia, la reingeniería gerencial, los sistemas de enseñanza-aprendizaje, la modernización irrumpe también sobre todos los que habitamos en el sector privado. Desde este punto de vista, la modernización es un concepto más amplio, más universal que nos reta a todos.

Urgando un poco más en las propuestas de modernización da la impresión de estar frente a un concepto muy economicista: menos Estado y más privatización. La modernización se centra en el uso eficiente de la propiedad. Pero la vida social y su modernización tienen que ser algo más que un litigio de propiedad pública y propiedad privada. A modo de ejemplo y pregunta, al acabar el año 1995, la Procuradora para la Defensa de los Derechos Humanos afirma que "El respeto a los derechos humanos y la solidaridad son fundamentos indispensables para la democracia y la seguridad ciudadana". Esta afirmación parece que no entra 
en la traducción economicista de la modernización. Tampoco entran los subtítulos de este mensaje de navidad: "La impunidad es la principal causa de la violencia que afecta a la población. El Estado tiene el deber de hacer cumplir el principio de legalidad y no debe propiciar actos ilegales. El goce de los derechos económicos y sociales se deteriora crecientemente. La modernización del Estado y la internacionalización de la economía no deben ser contradictorios con el respeto a la legalidad, la equidad y la solidaridad". En este mensaje, la procuradora nos ofrece un concepto más universal de modernidad: "La paz social, el Estado de derecho, la modemización económica, la lucha contra la impunidad y la inseguridad pública, la defensa del principio de la legalidad y la protección de los derechos humanos, son componentes interrelacionados de la gobernabilidad y la irreversibilidad de los acuerdos de paz"l. Por lo tanto, la modernización no puede ser un concepto restringido y economicista, sino tan universal como la paz social.

Una segunda pregunta es si modernización significa sólo lo más actual, lo que está de moda, o significa algo más perenne, que no quedará obsoleto cuando pase la moda. La comparación es clara y se refiere a los cambios estacionales del vestuario masculino y femenino impuestos por el marketing. La modernización expuesta por la Procuradora para la Defensa de los Derechos Humanos sí encierra valores y objetivos perennes, ya sea que miremos hacia atrás o hacia adelante de nuestra historia. Legalidad, derechos humanos y paz social son valores perennes. En cambio, el concepto economicista de modernización tiene mucho de marketing impuesto por el modelo económico de turno. Los modelos económicos son como los imperios o, mejor dicho, son imperios que crecen, dominan e imponen sus normas, tal como lo ha demostrado en varios casos el presente siglo. Los valores y los principios permanecen, pero los imperios pasan o se autodestruyen. Por eso, la modernización debe concentrarse en recuperar valores perennnes, en corregir problemas perennes, en modernizar humanamente la historia. Los litigios en torno a la propiedad privada han hecho la modernización más conflictiva. Lo adecuado sería tratar el tema de la propiedad pública y privada desde el supuesto filosófico del destino universal de los bienes materiales, es decir, los bienes son para todos los seres humanos. Este sí es un principio perenne.
Si la modernización es algo universal y perenne, que nos reta a todos, una tercera pregunta es quién o quiénes deben definir el concepto y cl contenido de la modernización. Conociendo la madera de que estamos hechos, cada cual o cada grupo puede emitir una definición y una agenda de modernización a beneficio propio. Por ejemplo, $L a$ Prensa Gráfica amaneció el 2 de enero con un gran titular: "Año de modernización. El presidente de ANEP y gremiales". El subtítulo rezaba: “1996, modernización, consenso" - Piden reducir el impuesto sobre la renta para empresas y asalariados", "Sugieren independencia política para el Banco Central de Reserva...". Las agendas podrían multiplicarse, lo cual es comprensible porque la modernización significa cambios bruscos y adaptaciones difíciles en el modo de pensar, en el modo de actuar y de producir, en el modo de relacionarnos socialmente.

Algo de esto hemos visto a lo largo de 1995. Los diarios y los representantes del sector privado le diseñaron la agenda de modernización al Estado, a beneficio siempre del sector privado. Pero desde el sector público les devolvieron el boomerang con el reto de la reducción arancelaria. Además, el sector público ha lanzado el reto de la modenización a todas las instituciones dedicadas a la educación nacional con las leyes de la Carrera Docente y de la Educación Superior.

Citar estas dos leyes referidas a la educación no es en razón de poner un ejemplo cualquiera, sino para introducir en la agenda de la modernización al ser humano y su educación. Es una oportunidad para dar voz a quienes no tienen voz, a quienes no se les pregunta qué es para ellos la modernización, aunque sí tienen la respuesta. $Y$ es posible dar una versión con la siguiente propuesta: el ideal y el supremo objetivo de la modernización se resumen en el logotipo o conclusión final de la cumbre mundial para el desarrollo social, Copenhague, en marzo de 1995: las sociedades prósperas son las que existen en función del ser humano.

\section{Las sociedades prósperas son las que existen en función del ser humano}

Es claro que este logotipo no encaja con otros conceptos de modernización, concretamente los aplicados a la restriccción del espacio y las funciones públicas, a la privatización de los activos y los 
quehaceres estatales, a la misión de subsidiaridad gubernamental, a la sola tecnificación administrativa y a la reducción de plazas en el sector público. Por supuesto, estos temas también hay que analizarlos. Es claro que este logotipo no encaja con los principios de modernización del neoliberalismo imperante, porque el desarrollo de los seres humanos es un futuro o un más allá que brotará de la sumatoria de crecimientos individuales presentes. Para el neoliberalismo, las sociedades prósperas se miden por el crecimiento de otras variables macroeconómicas, tal como nos lo enseñan algunas instituciones gubernamentales.

Dado que este logotipo de Conpenhague no encaja con las lecturas usuales de modernización, vale la pena hacer un esfuerzo para legalizar esta hipótesis de trabajo. Decimos que modernización debe ser un concepto y una realidad universal, perenne y ejecutada entre todos. El logotipo de Copenhague cumple con estas tres condiciones, tanto por lo que se refiere al término "las sociedades" como a su centro "el ser humano". El ser humano es lo más moderno que existe, precisamente porque es lo más antiguo: el ser humano siempre ha sido moderno o moderno a medias. Moderno a medias porque el ser humano siempre ha existido, pero ni antes ni ahora ha sido tratado, por lo general, como ser humano. Este ha sido el problema siempre moderno en la historia de la humanidad. Si en marzo de 1995 nos dicen desde Copenhague que los tres grandes problemas son la pobreza generalizada, el crecimiento con desempleo y la insolidaridad social, la modernización universal no va a hallar rspuestas fehacientes en los fríos principios individualistas del liberalismo, ni en una subsidiaridad restringida estatal.

Se impone confrontar las definiciones y los parámetros concretos de la modernización con este principio regulador: las sociedades prósperas son aquellas que existen en función del ser humano. Este ha sido ret gran litigio del pasado y del presente quinquenio. La discusión de las élites se ha centrado en la aceleración o desaceleración del crecimiento económico, en el volumen de las reservas netas, en el porcentaje del déficit fiscal, en lo manejable o en lo peligroso de la brecha comercial... Está bien y es necesario medir y hablar de estas variables macroeconómicas, pero ellas ni bastan ni logran el desarrollo del ser humano. El impacto de los documentos previos y de las relaciones de la cumbre de Copenhague hizo que se hablara por un tiempo del plan de desarrollo social, relegado actualmente a lo que pueda dar de sí el controvertido presupuesto estatal de 1996. Si las sociedades prósperas son las que existen en función del ser humano, llama la atención que no tengamos un rumbo nacional, un plan escrito y descrito de desarrollo económico y social, que incluso las gremiales privadas están pidiendo, bajo la forma de políticas sectoriales que remedien la desintegración económica interna.

Tal vez se trate de cuestiones linguísticas, pero para el presidente de la república son algo soviéticos quienes le solicitan estos planes de desarrollo. Da la impresión de que nos confiamos a las fuerzas imprevisibles del mercado, de la globalización, de los imperativos de las grandes instituciones financieras, de lo impuesto desde fuera más que de las demandas sociales que nacen de dentro. Un signo de nuestra antimodemidad es que la mayoría de los seres humanos, aquí y en otros continentes, no comprenden ni pueden comprender cómo un crecimiento real macroeconómico se traduce en un perenne encogimiento de sus microeconomías familiares, sin hablar de otras penurias de inseguridad personal y jurídica.

La universalidad de la modernización, incluyendo la recuperación de los valores éticos y cívicos tan deteriorados, lleva a limitar su ámbito a la esfera del Estado. Sin embargo, es un buen ejercicio reflexionar sobre las exigencias de modernización del Estado, porque lo que le digamos a él lo podemos aplicar a la sociedad entera, a los que habitamos el sector privado.

\section{La modernización del Estado}

La modernización del Estado significa la adecuación de la estructura organizativa y de su personal administrativo a las funciones que la cambiante historia le va demandando. Es la historia nacional y mundial la que determina sus funciones y responsabilidades. Por lo tanto, el término modernización es una responsabilidad dependiente de determinadas funciones. Más directamente, podemos preguntar cuáles han sido y son las funciones 
del Estado. El problema es que la historia de ayer $y$ de hoy no es la misma, ni siquiera en las diversas naciones actuales es la misma. Además, a los estados les ha tocado hacerse cargo de funciones no realizadas o no bien realizadas por otros sectores sociales. Siendo el Estado una institución humana y sus gobiernos entes transitorios, es históricamente cierto el fallido cumplimiento en algunas o en bastantes de sus crecientes funciones. En el ámbito de la modernización y las funciones del Estado hay que ponderar dos aspectos: el cuantitativo de mayores y menores funciones y el cualitativo de capacidad e integridad en su cumplimiento. Quizás haya una correlación entre lo cuantitativo y lo cualitativo, de acuerdo al refrán que el que mucho abarca poco aprieta. Además, el análisis de la modernización de las funciones del Estado nos lleva a considerar la modernización, las funciones y las disfunciones del sector privado.

En el presente siglo, la modernización del Estado se ha realizado en dos etapas de signo contrario, que recuerdan el movimiento de diástole y sístole del corazón humano. Al referimos a todo un siglo se impone la simplificación. Si el siglo XIX fue el siglo de la inversión privada, el siglo $\mathrm{XX}$ lo fue de la inversión pública. Quizás el siglo XXI vuelva a ser el siglo XIX, en octava mayor de las transnacionales. Esto quiere decir que hemos sido llevados secuencialmente por la mano invisible de A. Smith (a él se la cuelgan) y de la mano visible de los estados. Y a ninguna de las dos le ha ido del todo bien en la historia. Si en el presente siglo ha habido uno o dos cambios de mano, tenemos que analizar, de acuerdo a la historia, quién y quiénes no cumplen con sus funciones y no ceñirnos sólo al Estado.

Allá por los años de 1930 se quebró la mano invisible. Esa crisis mundial era la decimotercera, la más larga y profunda de la economía liberal de mercado. Los más jóvenes y también los más entrados en años no podemos olvidar esta profunda crisis de la economía de mercado, que hoy vuelve a reclamar sus derechos de primogenitura.

\section{3.l. La diástole del Estado}

Sin hablar de quienes, por razones ideológicas e históricas, se pasaron al extremo opuesto del péndulo económico e iniciaron la ruta de los socialismos reales, en el gran occidente, por razones de sobrevivencia y propia seguridad, se inicia la primera modernización estatal, inspirada en la teo- ría general de Keynes. A esta fase de ensanchamiento de funciones la denominamos la diástole del Estado. Modernización significó la reforma monetaria de Bretton Woods, la elaboración de los planes quinquenales de desarrollo, la confección de matrices intersectoriales como instrumentos de análisis y planificación económica, las grandes inversiones físicas, primero de reconstrucción y luego de expansión económica, la asignación de tratados de integración económica, los crecientes presupuestos estatales... Modernización significó la gestación de una extendida red de seguridad social, dada la presencia de fracciones prosocialistas en bastantes gabinetes de gobierno. Con el advenimiento de la guerra fría y las amenazas de las guerras calientes, pronto se agregarán los enormes presupuestos militares y los pactos de mutua defensa.

Al ampliarse la funciones estatales se incrementaron las instituciones autónomas o dependientes de los ministerios centrales, y aumentaron los fondos públicos adscritos a la contabilidad nacional; nacieron otras instituciones para controlar las finanzas públicas y la deuda externa. En esta fase de diástole, la administración pública absorbió riadas crecientes de empleados de mayor a menor cualificación técnica. Al igual que las medallas, esta fase tiene su anverso y su reverso y a cada cual le gusta mirar un sólo lado. Conviene mirar ambos lados, porque la historia es maestra de la vida.

\subsubsection{Uno por más y otros por menos}

Keynes dijo que la economía, dejada a sí misma, no caminaba espontáneamente hacia un crecimiento sostenido y que trece crisis en poco más de un siglo eran suficientes para justificar la guía de la mano visible del Estado. Keynes murió luego de Bretton Woods, pero las sacudidas de 1970 , $1980,1989 \ldots$ le siguen dando la razón, aunque digan que su teoría general ya no es tan general. De todas formas, Keynes dijo algo que sigue siendo verdad, que no sólo el Estado es el problema.

Si de la macro descendemos a la microeconomía, ya desde el siglo pasado nos encontramos con los grandes oligopolios, cárteles, monopolios y el gran capital financiero ( $R$. Hilferding), que controlan y dominan el mercado nacional y compiten agresivamente en la periferia internacional. Como ha descrito ampliamente J. Schumpeter, estas grandes empresas gestaron las revoluciones 
tecnológicas que, en el mediano y largo plazo, benefician al usuario final. Al mismo tiempo, su competencia interna e internacional derivó en nuevas crisis, tal vez en la primera guerra mundial. Siendo tan grande su poder, el mismo afán de ganancia que las mueve ha provocado de tiempo en tiempo sus quiebras.

La gran crisis se inició en la bolsa de valores, cuando la cotización de sus tílulos subió muy por encima de los rendimientos esperados, truncando a la mitad el nivel real de la producción y de los precios. La crisis de octubre ya pasó, pero la especulación rentista y el afán de ganancia a cualquier precio permanecen siempre en el corazón de la economía de mercado y puede hacerse presente en la bolsa de valores, en el proceso de privatización y en la creciente terciarización económica. La especulación, en cuanto arte de vivir del trabajo ajeno, es compañera peligrosa de la economía de mercado. En la solicitada privatización no sólo se busca la efíciencia económica. Al igual que la bolsa de valores, unas florecientes variables macroeconómicas pueden ocultar una estructura productiva interna débil, incapaz del crecimiento sostenible. A comienzos del siglo, la economía de mercado mostró un conjunto de debilidades económicas y sociales.

El crecimiento de la mano visible significó, entonces, el encogimiento o al menos la supeditación y el control del sector privado. Los motivos no eran solamente consecuencia de las crisis, quiebras y gestaciones masivas de desempleo (las crisis económicas eran crisis sociales), sino de la necesidad de constituir poderes compensadores. En cualquier texto de introducción a la economía encontramos el historial de leyes y medidas para controlar los oligopolios, los cárteles y los monopolios. Este control, expresado en forma negativa, o esta defensa de la competencia transparente, aparece como uno de los puntales de la economía social de mercado, a la alemana (A. Muller Arnack y Ludwig Erhard), que a veces citan nuestros gobiernos. El Estado aparece como un poder compensador, controlador o regulador.

\subsubsection{La planificación privada}

Históricamente, los oligopolios y monopolios tienden a practicar la denominada producción malthusiana, es decir, menor a la requerida socialmente para mantener los precios elevados. Cuando los oligopolistas descubren que el mayor beneficio es la tranquilidad, sustituyen la competencia agresiva por los convenios explícitos e implícitos, donde se respetan las cuotas individuales, que auguran buenos beneficios generales.

Cuando se generalizan las matrices insumoproducto, se observa que quienes dominan determinados sectores claves (columnas y filas de la matriz) controlan la economía nacional, pero no a beneficio nacional. Este fenómeno lo habíamos observado al analizar nuestra matriz de 1978, publicada por el Banco Central de Reserva en 1986. W. Leontief dijo que en Estados Unidos que quienes más analizaban las matrices insumo-producto eran las grandes empresas, porque les mostraban dónde canalizar sus grandes inversiones. De ello, K. Galbraith deducía que la economía estadounidense estaba planificada por la gran empresa. Progreso tecnológico, eficiencia, rentabilidad y planificación económica pueden repetirse en la globalización privada del mercado y no a beneficio social.

Esta tendencia del mercado a planificar sutilmente la economía generó un proceso de nacionalizaciones o de administración compartida, según los casos, en las ramas claves de la producción. De esa época data la legislación del control monopólico. Muy en resumen, testigo la historia, pode- 
mos concluir que el modelo de propiedad privada no fue un modelo de propiedad social. El afán de ganancia taponó la salida del "derrame", siendo menester erigir el poder compensador de la legislación social obligatoria, que no emanaba de los principios liberales. Sacando aplicaciones del pasado para el presente, dados los procesos actuales de terciarización y privatización económicas, que sumados significan desintegración productiva interna, nos asalta el interrogante de si el gran capital y el mercado derivan hacia sectores de mayor rentabilidad, abandonando los sectores tradicionales con mayor dinámica intersectorial y capacidad para asentar un crecimiento sostenible. La rentabilidad monetaria privaría sobre la productividad social y el corto sobre el largo plazo.

Llegamos a una no pretendida conclusión. Esta fase de diástole o de ensanchamiento del Estado tiene dos componentes: las crecientes funciones públicas derivadas de las crisis, guerras, reconstrucción, mercados comunes, carrera armamentística... y también las disfunciones o fallas económicas y sociales derivadas de las leyes y prácticas del mercado. Al igual que en el corazón humano, la sístole sucede a la diástole, parece que la historia recomienda aligerar el peso y el tamaño del Estado, quedando siempre una pregunta: ¿han disminuido las funciones del Estado? ¿Son otras sus funciones? ¿Incumplió el Estado sus funciones?

\subsection{La sístole del Estado}

Hay que mirar el reverso de la medalla, porque tampoco la propiedad pública o estatal ha sido siempre propiedad social a beneficio de todos. A los amplios poderes económicos y sociales del Estado se fueron agregando el poder y el gasto militar. El siglo XX ha sido el gran productor de dos guerras mundiales, de continuas guerras civiles y de la agotadora carrera armamentística. A la fuerza económica se agrega la fuerza armada y la producción bélica es tan grande o mayor que la producción civil. De esta forma el Estado son dos: la autoridad civil y la autoridad militar. También han sido dos los presupuestos nacionales. Tanto en las grandes potencias como en las pequeñas repúblicas, el presupuesto militar ha sido secreto real o camuflado, incluso para la contabilidad nacional. La simbiosis estatal-militar aparecía bastante clara en aquellos países donde los turnos presidenciales se hacían de militar a militar y donde los procesos electorales se convertían en romerías cívicas. Esto ha dado lugar a que por décadas los estados hayan practicado un nuevo sistema de poder: monopolios con guardaespaldas. De aquí se han derivado muchos males económicos y sociales.

Sin alargarnos mucho en el caso de los socialismos reales, que además nos quedan un tanto lejos, su propiedad estatal (o propiedad del pueblo entero, que decía su articulado) no fue una propiedad social a beneficio equitativo del todo el pueblo. Fue una propiedad estatal, creada por el pueblo, pero administrada privadamente por una relativa minoría. Baste agregar que el propio M. Gorbachov, en su Perestroika, afirma que en la URSS se aplicó el "principio del residuo" para la producción civil. El poder estatal no fue social. En este punto no hay mayor desacuerdo.

\subsection{1. ¿Son los gobiernos enemigos del Estado?}

Viniendo más cerca de nosotros y siempre sobre el tema de la modernización del Estado, con sus grandes funciones, poderes y responsabilidades, es posible enunciar una tesis: frecuentemente, los mayores enemigos del Estado han sido los gobiernos. La tesis es probable, porque Estado y gobiernos son dos entes diferentes: el primero es singular y perenne, mientras que los segundos son plurales y transitorios. El Estado es algo perenne, sus funciones y responsabilidades vienen del largo plazo y tienen por horizonte el largo plazo. Sus funciones y responsabilidades requieren, por lo menos, dos cualidades: son funciones muy técnicas y muy sociales. Cualquiera de estas dos cualidades que falle lo llevan a un populismo político y engañoso o un tecnocratismo frío y sin corazón. Estas suelen ser las acusaciones que el partido en el gobierno hace a los gobiernos anteriores o que la oposición hace al gobierno actual.

En este tren del Estado se montan, por turno, los sucesivos gobiemos y descubren, lo primero, que cuentan con un gran poder y con cuantiosos fondos disponibles. Las funciones y responsabilidades se insertan en los discursos públicos, porque pertenecen al largo plazo, mientras que el poder y los fondos disponibles se terminan en el más corto plazo. La ironía tiene algo de realidad porque el primero en criticar a los gobiemos anteriores es el gobiemo actual. Cada uno promete cambiar para mejorar. He ahí el problema de cómo lanzar un puente entre la perennidad del Eslado y la transitoriedad de los gobiernos. 
Uno de los puentes es el equipo de técnicos actualizados y más permanentes, que debiera mantener las instiluciones públicas, sin peligro de desmembramiento a cada vaivén político. Estos equipos técnicos actualizados y parcialmente renovables son los conocedores y portadores de la "tradición económica, entendida etimológicamente como la trayectoria de los problemas y desafíos económico sociales, que la historia anterior entrega a la presente. Esta relativa permanencia no se asegura si los equipos técnicos nacionales no son equitativamente remunerados, si son sometidos a la veleidad o incompetencia de las jefaturas políticas o si son supeditados a la gracia y buen querer de asesores externos de moda, quienes a veces dan la impresión de ser "inteligencias golondrinas" en busca de un nido donde encubar experimentos económicos. No estaría de más hacer una tesis sobre las migraciones de estos técnicos de institución a institución pública y del vuelo final hacia el sector privado. Frecuentemente, por culpa de los gobiernos, el Estado se ve privado de la requerida base técnica.

Otro puente fundamental entre lo perenne y lo Iransitorio, entre lo estructural y lo coyuntural son los planes de desarollo. Se trata del trabajo interinstitucional de los equipos técnicos, el cual arranca de la situación global y sectorial reciente y proyecta alternativas necesarias, realistas y posibles para el quinquenio próximo. En los países en desarrollo, el tiempo de los planes de desarrollo no ha pasado, máxime cuando se cierne una desintegración económica y social. Hay otro gran aporte que estos planes de desarrollo pueden dar a los gobiernos. Ante un plan de desarrollo, técnica y objetivamente elaborado, el gobierno puede descubrir qué funciones le competen al Estado y qué funcio-

nes puede y debe delegar, suprimir o transferir. Sin un plan de desarrollo, el gobierno será el primero en ignorar sus propias funciones y así puede desacreditarse, recurriendo a medidas improvisadas y sorpresivas.

\subsubsection{Conócete a ti mismo}

Brevemente, he aquí algunas de las funciones del Estado. Un plan de desarrollo, apoyado en las matrices intersectoriales de que disponemos y pue- den actualizarse, le permite al gobierno dialogar con los representantes de las diversas ramas productivas. El plan de desarrollo y las matrices describen la realidad económica presente y las potencialidades futuras, describen las fortalezas y las debilidades económicas. Este diálogo, propio de una economía concertada, hará aparecer públicamente qué función compete al Estado como orientador, regulador o productor dentro del conjunto económico; se justifican así las medidas macroeconómicas y sectoriales que deba tomar, de cara a la estabilización general y a la integración sectorial.

Este diálogo concertado ayuda a descubrir qué sectores y qué importaciones resultan más dinamizantes, qué sectores muestran una actualización tecnológica hacia dentro y hacia fuera, y qué sectores necesitan un apoyo o una corrección para inducirlos a la dinámica general. Este diálogo concertado nos ayuda a todos para comprender mejor que el proceso económico es algo intersectorial e interdependiente y que la buena marcha de unos sectores va unida a la buena marcha de otros. Un plan de desarrollo matricial nos ayudará a ver que la economía se realiza sobre nuestro espacio económico, por cierto dañado ecológicamente y desintegrado económicamente. El sector agrario ha caído en la desolación y en el abandono. Un plan de desarrollo matricial sirve para orientar la inversión privada y la pública, física y social. Directa o indirectamente se convierte en una guía para la canalización del crédito bancario.

Visto al revés, la ausencia o no publicación de un plan de desarrollo es una de las causales mayores de la sístole del Estado. El Estado, por culpa de los gobiemos, se convierte en el problema cuando no hace lo que debe hacer. También se convierte en el problema cuando descuida la administración técnica y su carácter social. Se extiende el clamor de la privatización, basado en la tesis de que el Estado es un mal administrador; con frecuencia los gobiernos dan motivos a este clamor y a esta tesis. Basten unos pequeños ejemplos.

La simbiosis del Estado y la fuerza militar generó una larga tradición de uniformados al frente de instituciones de servicios públicos, cuya gerencia requiere una notoria cualificación técnica. Es- 
tas grandes instituciones arrancan de estudios y proyecciones de la esperada demanda nacional, requieren la formulación y evaluación de costosas inversiones, de análisis geográficos de localización, de procesos transparentes en las licitaciones, de controles efectivos de los gastos y de la eficiencia en los servicios realizados. Estas instituciones tienen un carácter netamente monopólico y sus decisiones afectan verticalmente a toda la sociedad, sin posibilidad de réplica. Si por incompetencia gerencial se descuida la cadena del proceso, se agotan rápidamente los presupuestos, se recurre a subvenciones onerosas, las inversiones quedan a medio camino y se genera la conciencia de que la administración pública escapa a las normas universales de la gerencia eficiente y responsable. Falla el uso social de la propiedad pública cuando se olvida que la microcconomía es microeconomía para todos.

Si a la deficiencia lécnica se agrega la falta de honestidad, el público tendrá que cotizar la corrupción creciente. Por sumatoria de bastantes casos particulares se formula la tesis general de que el Estado es un mal administrador. Si adicionalmente, los ministros y presidentes de las instituciones públicas del actual gobierno publicitan la desnacionalización necesaria, esta tesis cobra mayor credibilidad. Un adagio romano dice que el abuso no suprime el uso, es decir, que lo que hay que suprimir es el abuso. Esto vale para toda clase de monopolios que derivan en el abuso. Parecería que algunos gobiernos se liberan de su obligación de corregir los abusos, transfiriendo el uso, sin ponderar si ello va a derivar en otros abusos. Algo de esto puede estar subyacente en el tema de la privatización.

Otro sacrificio que frecuentemente generan los monopolios públicos es "el tiempo de espera". $\mathrm{Pa}$ recería que estas instituciones ignoran que el tiempo tiene un valor, por lo menos para el usuario. Se trata de la burocracia y del instinto de poder, que sentimos al realizar ciertas actividades públicas. Es claro que algunas de estas actividades requieren un tiempo de espera: no es lo mismo comprarse un teléfono que lograr la instalación de una línea telefónica. Pero la verdad es que nos resulta cuesta arriba tener que renovar la licencia de manejar, el pasaporte nacional, sacar un embarque de las aduanas.... por mecionar ejemplos menores. La situación se hace más penosa a quienes vienen a hacer similares diligencias desde departamentos lejanos y razonablemente votan por la descentrallización.

Además, la burocracia, la cascada de firmas, sellos y trámites, derivados del instinto de poder, generan una mala imagen en la base de empleados subalternos, que no tienen más poder que el de decimos: vuelva mañana. Para recortar los trámites de servicios públicos se inventó la mordida, que es otro impuesto al impuesto al valor agregado, que no entra en el erario público. Entrados en la revolución telemática, las computadoras podrían recortar los tiempos de espera, pero sólo la tecnología no puede corregir el instinto de poder de algunas jefaturas públicas, la desatención a los no pudientes y otros vicios que nos recuerda la Procuradora para la Defensa de los Derechos Humanos. No es sólo cuestión de más o de menos funciones, sino de cómo funcionan las funciones.

\section{La socialización de la privatización}

Los movimientos de diástole y sístole del Estado y de la administración pública parecen encarrilarnos hacia la privatización: extender el ámbito de la propiedad, la responsabilidad y la iniciativa personal. El ideal sería que el proceso alcanzara a los más o a todos los miembros de la sociedad. A esto llamanos la socialización de la privatización, de acuerdo a nuestro lema: las sociedades prósperas son las que existen en función del ser humano.

El problema es que la modernización y la privatización del Estado no se están entendiendo de este modo, dado el temor que los privados de propiedad, iniciativa y responsabilidad manifiestan ante el anuncio de la privatización. Nos enfrentamos a dos conceptos muy distintos: un concepto oficial y del sector privado que busca transformar propiedad pública en propiedad privada, y un concepto de seres humanos que busca transformar la propiedad privada en propiedad más pública, de más personas, más social. Son dos conceptos que caminan en dirección contraria. En buena parte, la historia de la humanidad ha sido función de la historia de la propiedad privada. Por lo tanto, hablar de la privatización es tocar un problema de la humanidad. Por ello es importante que reflexionemos sobre este tema, siempre de moda, la privatización.

\subsection{La modernización del neoliberalismo}

No basta anteponer el prefijo "neo" para acep- 
tar que el liberalismo es algo moderno, cuando conocemos los errores y fallas del mercado desde el siglo pasado y especialmente sus desfalcos sociales. Tampoco el desmantelamiento de las economías socialistas de Europa del este es un argumento valedero para coronar al neoliberalismo como la única solución. Siendo equitativos podríamos decir que los socialismos reales son culpables de la mitad de la historia o de la historia de la mitad del universo; la otra mitad, en el tercero y primer mundo hay que cargarla al debe del liberalismo.

Estando distribuido el mundo de esta manera, difícilmente se puede proclamar el fin de la historia. Si el neoliberalismo quiere ser moderno debe prestar más atención a sus críticos, que son más, que sus abanderados y beneficiados, que son menos. Los neoliberales deben aceptar que se hable más de ellos en el nuevo y en el viejo continente, que la libre iniciativa se traduzca en una libertad de diálogo, que a su libertad de imponer normas corresponda el derecho de reclamar deberes. Los neoliberales deben acostumbrarse a leer publicaciones como El liberalismo en cuestión ${ }^{2}$, escrito en el viejo mundo, y también entender que su economía de mercado es una parcela de un todo mayor: Etica, economía, política y pobreza ${ }^{3}$, escrito en el nuevo mundo. A mediados del siglo y desde un próspero país, los pensadores y actores de la economía social de mercado también los cuestionaron.

\subsection{Dos principios para una crítica}

Luis de Sebastián introduce el primer seminario con este cuestionamiento. "La crítica del neoliberalismo (tema central de este seminario) tiene que partir de un supuesto filosófico y de otro supuesto económico. El supuesto filosófico es el destino universal de los bienes materiales, que son para todos los seres humanos. El supuesto económico es que el comportamiento de los individuos en la esfera económica (el mercado) lleva necesariamente a conflictos de intereses que sólo pueden ser resultos o moderados por una instancia exterior al mercado: una clase social, el Estado, la Iglesia o la sociedad entera. Para el neoliberalismo, los fenómenos que desde una visión ética de la realidad socio-económica llamamos 'conflictos' (explotación, pobreza, desempleo, fuga de capitales, quiebras bancarias, crash de la bolsa, enfrentamientos regionales...) son episodios necesarios y positivos de la lucha de los ejemplares más fuertes de la raza humana para conseguir mayor riqueza, mayor prosperidad, mayor bienestar para la humanidad en general, aunque no necesariamente para todos y cada uno de los miembros de esa raza. Pero eso no importa: la humanidad se considera mejorada sólo con que algunos de sus miembros alcancen niveles nunca alcanzados de riqueza. Es un desarrollo vicario, en que los ricos ejercen la función de representar a toda la humanidad en el disfrute de los bienes materiales de la creación"4.

El Dr. Hans Jurgen Rosner, de la Universidad de Colonia, enumera similares principios al esquematizar los fundamentos teóricos de la economía social de mercado. "Por más importante que sea la funcionalidad del mercado para el eficaz ordenamiento de las actividades económicas, ello no puede significar que el hombre se rinde ante un mecanismo que desconoce valores, y al cual todos los demás aspectos de la existencia humana tienen que subordinarse. Al contrario, debido a que la historia nos enseña que la libertad y la dignidad del hombre dependen en gran medida del orden económico, es el hombre quien debiera ser autor, centro y objetivo de toda economía. En esta estricta referencia conceptual a la naturaleza del

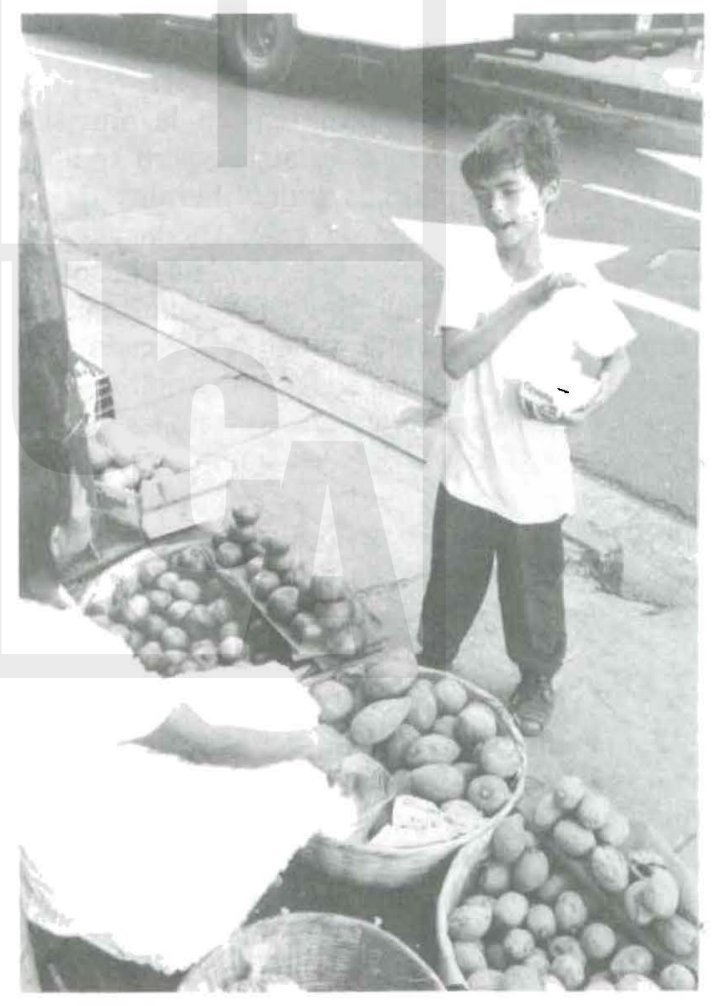


hombre como persona individual así como ser social, la economía social de mercado se muestra fuertemente influída por la doctrina social de la Iglesia. El reconocimiento de la supremacía de fines humanos sobre objetivos económicos reclama cumplir con dos objetivos. Primero: la formación económica no debe realizarse aislada de la formación general de la existencia humana, sino que tiene que estar subordinada a ésta. Segundo: el mercado y la competencia requieren de un código ético que preserve el bien común a través de un marco de condiciones sociales, que al fin y al cabo sólo puede ser establecido y garantizado por el Estado"s.

Esta cita, que a su vez integra referencias a tres diferentes autores, proviene de pensadores que defienden la eficiencia del mercado ordenado. Ellos se autocalifican como "ordo-liberales". Los tres pilares de su concepción son la aspiración a encontrar una síntesis entre la libertad personal y las obligaciones sociales del comportamiento humano, la competencia como principio creador y estímulo del proceso económico y la combinación sinérgica entre la eficiencia económica y las exigencias de justicia social6.

Los ordoliberales, supervivientes del nacional socialismo y hermanos separados de la Alemania Democrática, no comulgan con el dirigismo de la planificación central, no confían en la previsión superior de los burócratas estatales, pero se apartan de las concepciones paleoliberales de un capitalismo salvaje, que da valor solamente a la libertad personal y olvida los valores de la solidaridad y la justicia social. El objetivo de los autores y actores de la economía social de mercado es la integración de la política social en la política económica. "En la medida en que esto no se logra, o sea en la medida en que los hombres viven en denigrante pobreza o que se les deban repartir los bienes esenciales fuera del proceso de mercado, la economía de mercado es imperfecta y debe ser complementada a través de la política social "7.

\subsection{El mercado no es un juego}

Estos autores no aceptan que su coterráneo F. August von Hayek vanalice el objetivo "social" como agente perturbador de la economía de mercado, y que, de acuerdo al Diccionario de Oxford, compare la competencia del mercado con un "juego": "según esto, así como es ilógico calificar de justo o injusto el resultado de un partido de fútbol si los equipos han jugado limpio y conforme a las reglas, igualmente ilógico es decir que los resultados del proceso de mercado son justos o injustos, si todos los participantes han actuado de acuerdo a reglas de competencia justas" 8 .

R. Jacob reacciona con mayor racionalidad. "Una posición tan unilateral como ésta no va de acuerdo con el concepto de la economía social de mercado. La economía, que está llamada a crear las bases materiales para una vida humana digna, no puede ser reducida a un juego en los mercados y reglas leales de competencia. Cuando se pierde un juego de fútbol no es una cuestión existencial. En relación con la economía, sin embargo, casi para todos los hombres se tratan de cosas existenciales... Los liberales insultan a los pobres con su arrogancia, queriéndoles hacer creer que no tienen suficiente éxito en el 'juego del mercado', porque son muy tontos o muy holgazanes o porque simplementre han tenido mala suerte por su origen. Según esta posición liberal de von Hayek, lo único que se puede hacer con los pobres es evitar que se mueran de hambre dándoles limosnas"'.

No nos estamos olvidando de la socialización de la privatización al dar este rodeo por la economía social de mercado. La privatización gira en torno a la eficiencia del mercado y confía en las reglas de la libre competencia. Las reglas justas y limpias, dirá R. Jacob, "sólo tienen sentido cuando todos los participantes tienen condiciones de partida similares y existen para todos oportunidades de ganar... Esto aplicado a la economía significa que los resultados y oportunidades de ganar en el "juego del mercado" no dependen solamente de la limpieza o justicia de las reglas de la competencia, sino también de las condiciones de partida, sobre todo de la distribución de los ingresos y del capital. Si se supone que el juego del mercado debe tener éxito, debe existir una distribución de los ingresos y del capital que le dé oportunidades de éxito a la mayor cantidad posible de personas. Lograr esta distribución es una tarea importante de la política social"10.

\subsection{Nuestro terreno para el juego del mercado}

En forma similar se expresa el Dr. H. Jurgen Rosner, haciendo una aplicación a América Latina. "El objetivo es lograr que los esfuerzos para la realización de los intereses particulares en competencia sirvan positivamente a un desarrollo socioeconómico en beneficio de la mayoría. Al 
Estado le cabe la tarea de establecer y observar cicrtas 'reglas del juego' para equilibrar la división de los poderes políticos, económicos y sociales y para evitar así que transitorias posiciones de superioridad se transformen en monopolios u oligopolios permanentes; que se desnaturalice o elimine la competencia con la formación de carteles y se paralice la fuerza y presión innovadoras; que se impongan intereses regionales, sectoriales o particulares a costa de otros. El segundo requisito para llegar a una política económica y social integrada radica en la delimitación exacta de los derechos de propiedad privada para que se equilibren la eficiencia económica y la obligación social".

Lucgo de comentar cuatro instrumentos o políticas que puede aplicar el Estado a este fin, desciende a describir nuestro terreno para el juego de mercado. "No obstante, en la realidad económica de América Latina, la omnipresencia de las ganancias oligopolísticas, monopolísticas o especulativas así como de rentas derivadas de derechos de disposición no sólo son fenómenos bien conocidos sino, muchas veces, admitidos legalmente. En segundo lugar, como ya fue mencionado, los neoliberales tienden a olvidar las desigualdades existentes en las condiciones de partida, una negligencia grave si se toma en cuenta que casi todos los países latinoamericanos están caracterizados por sus extremas discrepancias en la distribución de los bienes, sea de los capitales financieros, sea de los medios de producción o sea de la tenencia de la tierra. Este hecho lleva consigo que la distribucón primaria del ingreso por el mercado reproduzca, en forma cada vez más acentuada, las desigualdades ya existentes. Bajo estas circunstancias, la competencia en el mercado no es leal, sino que es una competencia entre desiguales, donde los que disponen de mayor poder económico continúan acumulando su riqueza en desmedro de los que tienen menor poder".

"Este fenómeno" —continúa nuestro autor, "no sólo fortalece las tendencias de monopolización ya inherentes en las economías latinoamericanas sino que impide, también, gravemente un desarrollo sostenido en el que faltan las amplias clases medias, que caracterizan todos los países más avanzados. En su lugar, las sociedaddes latinoamericanas, muchas veces, se presentan en forma piramidal, es decir, caracterizadas por una base demasiado grande formada por las clases humildes y dominada por una capa privilegiada muy pequeña.
Así, las economías latinoamericanas casi siempre se encuentran en una latente crisis de estancamiento coyuntural porque las masas populares no disponen de bastante poder adquisitivo para desplegar la demanda interna necesaria para soportar un continuo proceso de crecimiento económico sostenido... Los medios previstos en el concepto de la economía social de mercado para lograr esta compensación son tres: la política fiscal redistributiva, la política social compensatoria y la autonomía gremial"II.

\section{4. ¿Una distribución escatológica?}

Como indica Luis de Sebastián, el proceso distributivo que los neoliberales relegan al final de los tiempos ha generado, bajo diversas formas, la necesidad de políticas redistributivas. "Esto nos lleva a insistir en la re-distribución de los frutos del trabajo, del capital y de la tierra (y otros recursos naturales) de una manera más coherente con el destino universal de los bienes. La distribución que los neoliberales relegan al final del proceso de crecimiento, convirtiéndola en una distribución escatológica, o sea, al final de los tiempos, tiene que ser el grito de movilización contra el neolibe-

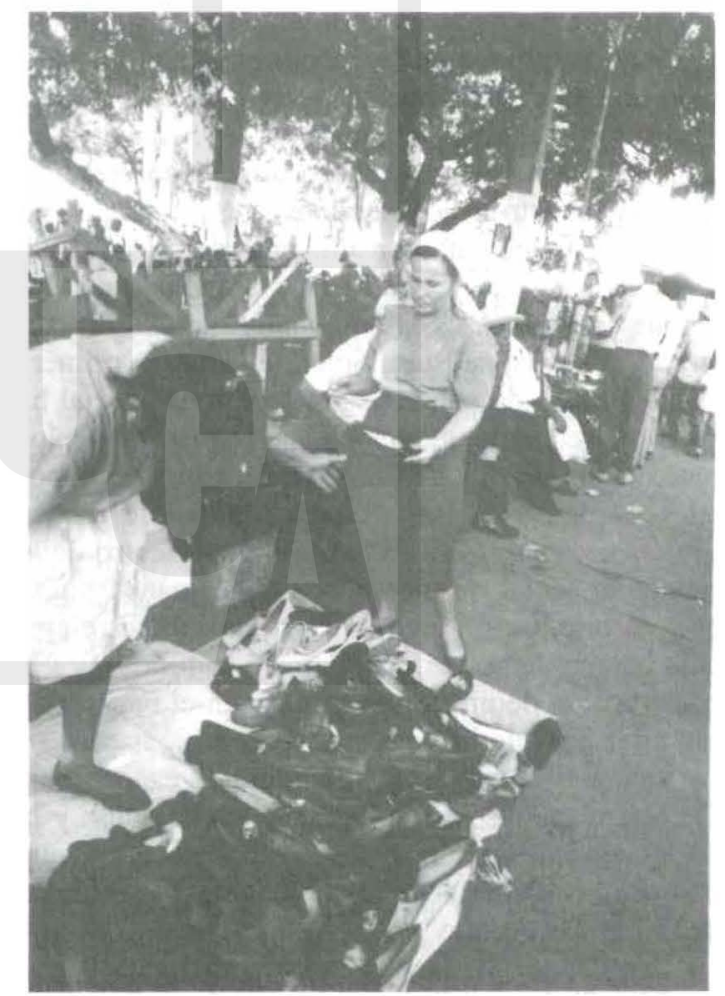


ralismo. El efecto 'rebalse', es decir, que llegue a los niveles inferiores de ingresos lo que sobra en los superiores, no es aceptable éticamente ni funciona adecuadamente... El proceso de distribución del producto nacional es un proceso conflictivo en el que priman las relaciones de fuerzas de los distintos grupos que se disputan el pastel; que la distribución del producto dejada al mercado es desigual y normalmente injusta; y que la sociedad tiene que intervenir de alguna manera para moderar estos conflictos y redistribuir equitativamente lo que las relaciones de fuerza distribuyen con poca equidad" 12 .

Desde hace medio siglo la política redistributiva forma parte de la política social y de la política económica en la economía social de mercado, como uno de los instrumentos del crecimiento con equidad. "La tarea de la política fiscal redistributiva consiste en corregir mediante progresivas tasas impositivas las desigualdades excesivas en la distribución primaria del ingreso. La meta de tales medidas debería ser lograr una distribución personal de los ingresos de manera que cada uno contribuya a las cargas comunitarias en proporción a su potencial económico"13.

Aunque nuestros gobiernos, pasados y presente, dicen inspirarse en la economía social de mercado, la estructura impositiva tradicional y el alza del impuesto al valor agregado en 1995, como principal nutriente del presupuesto estatal, no concuerdan con la distribución equitativa de las cargas públicas. Otro elemento constituyente de la economía social de mercado y que ha sido dimidiado por los actuales gobiernos es la autonomía gremial de empresarios y sindicalistas. Sólo funciona la primera mitad. El foro de concertación económico social ha quedado reducido a una buena propuesta de los acuerdos de paz. "La formación de relacones laborales es de suma importancia, dado que ambas contrapartes cumplen un papel crucial dentro de la economía social de mercado. En Alemania, como base de orientación ideológica se presentaba el anhelo común de buscar conceptos y caminos para la construcción de un 'tejido social', en el cual todos los miembros de la sociedad pudiesen experimentar una consideración de sus intereses específicos. De esta manera se pudo lograr la pacificación y la integración de los diferentes grupos sociales, que demostró ser un factor estabilizante y promotor del bienestar general" 14.

De esta forma, la lucha de clases se convirtió en "contrapartes sociales", que iniciaron libremente medidas de conciliación, sin recurrir a un arbitraje o concilicación estatal obligatorios. El proceso de privatización de nuestras grandes instituciones de servicios públicos (ANTEL, CEL...) debiera tomar en cuenta a estas "contrapartes sociales" a la vista de las tensiones sociales generadas antes y a partir del primer decreto 471, si algo tenemos, como dicen, de economía social de mercado.

\subsection{Crecimiento con equidad}

Un aporte y un objetivo central de la economía social de mercado es el crecimiento con equidad. Aquí se integra toda la política social. "El Estado, la economía y la sociedad deben y pueden ordenarse de tal manera que ambos fines, el de crecimiento y el de distribución, no se contradigan, sino que se complementen, o sea, se condicionen mutuamente" (R. Jacob cita al Banco Mundial).

Diversos estudios han determinado que la educación es la variable que más influye en la desigualdad en la distribución del ingreso. Las inversiones en educación, salud y nutrición, si están bien concebidas y son bien aplicadas, pueden mejorar la distribución y, al mismo tiempo, promover el desarrollo por otros medios... Y a continuación una cita de Alfred Marsahll, del año 1890: "La salud y la fortaleza física, espiritual y moral... son la base de la riqueza industrial, al mismo tiempo, la importancia fundamental de la riqueza material radica en el hecho de que, si se administra sabiamente, aumenta la salud y la fortaleza física, espiritual y moral del género humano".

Con ello R. Jacob concluye: "El crecimiento económico requiere, sin lugar a dudas, inversiones para aumentar el capital físico. Pero, en primer lugar, el crecimiento económico es producido por hombres productivos y motivados. Por eso, la satisfacción de las necesidades básicas, el ataque directo contra la pobreza, las inversiones en capital humano, no son un despilfarro social, sino condiciones necesarias para el crecimiento duradero" 15. A continuación $\mathbf{R}$. Jacob, que trabajó por un tiempo en la Fundación Konrad Adenauer en El Salvador, desarrolla las medidas concretas que pudieran aplicarse en nuestro país para combatir la pobreza y para adoptar medidas de previsión social.

\section{Modernización: valores y contravalores}

Es claro que los modelos políticos y económi- 
cos se asientan en principios filosóficos, sustentados en valores éticos y ellos, a su vez, son confirmados por la historia. Por eso se da mucha importancia al conflicto de valores y a las justificaciones éticas y teológicas del neoliberalismo. A los principios éticos sobre la persona se agregan los aportes de la doctrina social de la Iglesia, la inculturación del evangelio, la opción por los pobres y la cultura de la solidaridad.

No me atrevo a decir si la historia crea los valores éticos o más bien los crean los intereses privados y grupales, porque frente a la misma historia surgen concepciones y valores éticos enfrentados. Es importante que nuestra reforma educativa insista en la formación de valores éticos y cívicos, más que en la sumatoria de conocimientos dispersos, porque de los valores surgen las actitudes y las acciones. Pero los valores surgen de una lectura crítica y objetiva de la historia; el problema es que la historia no trata igual a todos.

\subsection{La lucha de valores en el viejo mundo}

El cuestionamiento del neoliberalismo tiene lugar también en los países desarrollados, en la cuna del primogénito liberalismo. Como lo conocen bien pueden cuestionarlo. En este sentido, la siguiente cita, algo extensa, es interesante por su estilo y contenido. "Los problemas existentes desde hace más de un siglo en buena parte del planeta (marginación, bolsas de pobreza, falta de libertades, inmigración forzada...) siguen presentes en la actualidad, ya que no pueden desaparecer por arte de birlibirloque ni por pretendidos 'finales de la historia'. Desde la asunción de esta realidad, hay que reafirmar la bondad de un sistema político, social y cultural que refuerce los valores de libertad con justicia, solidaridad e igualdad para hacer frente a los valores insolidarios que predominan en nuestras sociedades desarrolladas, entre ellos, y no el menos importante, cl de la exaltación de la riqueza y del éxito económico, que contribuye a dejar fuera de la sociedad a un scgmento importante de la población".

A continuación la misma historia leída desde valores diferentes. "Buena parte de la cultura neoliberal imperante durante la década de los ochenta se ha construido alrededor de la lucha contra los valores desarrollados en Europa durante la posıguerra mundial; ejemplos claros y evidentes

serían la crítica descarnada a las instituciones del Estado de bienestar, la cultura del triunfo individual 'frente a los demás' y el ataque frontal a las organizaciones sindicales como pretendidos 'sujetos retardatarios' del progreso social. Pero la oleada conservadora no nos puede hacer olvidar que Europa se construyó sobre los valores de justicia, solidaridad y progreso, los cuales, a pesar de los ataques antes citados son valores que no han desaparecido. Estamos viendo ya, además, los efectos perniciosos que las políticas neoliberales han tenido en el terreno social en los dos países más significativamente abanderados de la revolución neoliberal (Estados Unidos y Gran Bretaña) y los costes económicos que han significado para una parte importante de la población [...] En tal tesitura, debemos contribuir a cambiar los vientos de la historia y recuperar - incorporando todo lo que de nuevo sea necesario- aquellos valores que posibilitaron el desarrollo de una Europa solidaria en la década de los sesenta y buena parte de los setenta. Además, nos parece útil y necesario deshacer un equívoco existente respecto al pretendido abstencionismo económico y social de los gobiernos conservadores. Si algo ha caracterizado en la pasada década a tales gobiernos ha sido un descarado intervencionismo en el ámbito económico - pero a favor del conglomerado militar en los Estados Unidos - y en el ámbito laboral, pero para restringir los derechos colectivos y sindicales en Gran Bretaña [...] En suma, debemos recapacitar sobre qué tipo de desarrollo propugnamos y con qué valores, teniendo bien claro que la competitividad es un valor que debe servir para el enriquecimiento colectivo y no sólo para provocar un agravamiento de las desigualdades, y que la 
economía no puede ser pensada independientemente de los cuadros institucionales y de la sociedad en que se inserta. El debate actual se realiza sobre el reparto de los frutos del crecimiento, lo que evidentemente es muy importante, pero no sobre el sentido y modalidades a largo plazo del desarrollo, lo cual no lo es menos"'16.

El conflicto de valores proviene del conflicto de objetivos en la práctica política. Luis de Sebastián sostiene que "hay un conflicto, el conflicto entre eficiencia y distribución, que no se puede ignorar en favor de ninguno de los dos términos con exclusión del otro. Esto teóricamente está muy estudiado, pero parece que resulta muy difícil realizarlo en la práctica política"17.

\subsection{Historia y teología neoliberal}

El problema que encuentran estos autores del viejo mundo es el triunfalismo y la mala memoria de los neoliberales. Para ellos no hay lugar a un cuestionamiento de su doctrina. Se fundamentan en argumentos históricos del corto plazo. La prueba mayor está en la descomposición interna de los sistemas colectivistas, centralmente planificados, opuestos a las libertades económicas del mercado y a la libre expresión política.

No es fácil convencer a un neoliberalismo triunfalista y de mala memoria, que selecciona los lados de la historia.
Por añadidura, existen autores que han tratado y siguen tratando de justificar la ética y la razón teológica del capitalismo y del neoconservadurismo. José María Mardones recopila los argumentos de un amplio grupo de autores, europeos y estadounidenses, que consagran la teologia política del neoconservadurismo. Josep Vives se centra específicamente en $\mathbf{M}$. Novak, un conocido autor. Los teólogos del capitalismo y del neoconservadurismo nos llevan a la idolatría del sistema. Es impresionante constatar cómo llegan a trastocar la buena noticia de la salvación a favor de las "minorías".

José María Mardones afirma: "El Dios neoconservador es un dios de ricos, privilegiados $y$ capaces. Ciertamente -contra Novak-, ofrece pocas afinidades con el Dios bíblico. Más bien es una tergiversación del mismo con la ptetensión de suplantar al verdadero Dios. Una estrategia que continuará. Los neoconservadores disponen para ello del triunfo mundial del sistema, pero carecen de la legitimidad del evangelio"18. José I. González Faus, teólogo reconocido concluye "que se nos hace preciso tomar conciencia de tres cosas: (l) el tejido social está enfermo; (2) el camino es malo: ricos cada vez más ricos a costa de pobres cada más más pobres; (3) ¿el fascismo que viene?". Este teólogo lanza la siguiente advertencia: " Occidente cuidado con perder tu alma!".

En un artículo no se puede ir más allá de algunos titulares y conclusiones. Lo importante es entender que el viejo mundo se une en este debate frente a un neoliberalismo de caras multifacéticas. Para el neoliberalismo el éxito económico es el objetivo central, aunque desde Copenhague, el primero y el viejo mundo les hayan dicho que también la economía anda mal: se generalizan la pobreza, el desempleo y la insolidaridad social. Como dijimos al principio, a los neoliberales les resbala el logotipo y la conclusión final de esta cumbre mundial.

\subsection{La lucha de valores en el viejo mundo}

Etica, economía, política y pobreza están muy correlacionados. Para el neoliberalismo somos un 
continente atrayente y repelente a la vez. Como tercer mundo somos una combinación del primero y segundo mundo. El liberalismo y el neoliberalismo siempre han encontrado muy buenos aliados en las aristocracias económicas y políticas, acuerpadas por las cúpulas militares, en nombre de la seguridad nacional. El continente latinoamericano ha sido también lugar de recepción y transmisión de las ideologías del segundo mundo y sus ensayos económicos y sociales siguen perturbando al "hermano mayor". Las razones son claras. El neoliberalismo sabe que tiene atractivo y tiene rechazo: el atractivo de quienes atraen cada vez más propiedad privada y el rechazo de quienes rechazan la propiedad privada.

El neoloberalismo predica la libertad política, la libre elección nacional, pero irrumpe violentamente en las decisiones públicas a través de las instituciones financieras internacionales que controla. El neoliberalismo sabe que si el dolar todavía no es aceptado como moneda nacional, la "dolarización" si es moneda corriente en el ámbito del alto juego político. La expresión monetaria de la corrupción es la "dolarización". Pero el neoliberalismo, sus principios y valores, encuentran la contrarréplica del mundo de los pobres, en sus valores humanos, su solidaridad y su hambre de justicia. En este continente ha brotado la sana

teología de la liberación y también sigue teniendo amplio vigor la enseñanza social de la Iglesia y los mártires que dan fe de la buena noticia en favor de los pobres.

\subsubsection{Los antivalores}

La realidad social en la cual viven millones de seres humanos es ampliamente conocida. Los extremos de miseria son intolerables y exigen esfuerzos concretos por parte de los gobiernos y la sociedad. Según el presidente brasileño Fernando Enrique Cardoso, el pueblo es el mayor activo estratégico de un país. Por consiguiente, la tarea es incorporar al proceso de desarrollo a los millones excluidos por la miseria. No sólo es una necesidad del desarrollo, sino también un imperativo ético. La persona humana y su dignidad, conforme lo enseña la doctrina social de la Iglesia, deben estar siempre en el centro de todo esfuerzo en la búsqueda del desartollo.
La respuesta política para revertir esta realidad no ha sido suficientemente adecuada, en particular por causa de una crisis ético moral no sólo en la práctica política, sino también en la vida social. Esta crisis se manifiesta de forma variada: corrupción, falta de prioridades y transparencia en el uso de los recursos públicos, mentira política en las campañas electorales y promulgación de leyes contrarias a los valores humanos y cristianos fundamentales.

El terce milenio que se aproxima es una oportunidad para hacer un diagnóstico serio, nacional y continental, de algunos aspectos de la realidad latinoamericana. El desarrollo con justicia social debe ser un compromiso de toda la comunidad internacional y de todas las personas, porque todos estamos llamados a cooperar en la construcción de un mundo más humano y fraternol9.

\subsubsection{Las propuestas}

Es indudable la existencia de mucha corrupción en la lucha por el disfrute político, que la mentira política ha minado la credibilidad y las experanzas de las mayorías, que hay formalidades de democracia que quedan diluidas por las discrepancias económicas, que el pueblo cada vez son más y cada vez es menos. Es conclusión cierta que con la comupción y la mentira política no hay modelo económico que aguante y si no se erradican, sólo habrá más décadas perdidas.

El orden económico es importante, pero no se puede poner ni imponer un orden económico mientras no se ataquen los vicios políticos, porque los políticos son quienes ponen e imponen el orden económico. Más que la carencia de recursos naturales y el retraso tecnológico, lo que frena el avance del continente es la perversión de los valores humanos y políticos. De ahí que la dignidad del hombre, la solidaridad como base de la sociedad y la pobreza como la mayor violencia sean temas relevantes para la economía.

En este esfuerzo, la Iglesia católica tiene una responsabilidad especial. Su doctrina social y los valores cristianos representan un aporte importante para los modelos económicos. La Iglesia y más concretamente las conferencias episcopales están obligadas a evaluar los modelos económicos y a 
dar orientaciones desde la doctrina social de la Iglesia. Juan Pablo II lo dijo abiertamente en Africa: "La Iglesia debe ser la voz de los que no tienen voz. La Iglesia católica en el continente debe servir como un perro guardián de la justicia y de los derechos humanos". El Papa pidió a las conferencias episcopales establecer comisiones de justicia y paz, donde no existiesen, para supervisar los derechos humanos, pues "la Iglesia tiene el derecho y el deber de ayudar a construir una sociedad justa, pacífica y pluralista". Después de estas exhortaciones sería triste que la Iglesia, en algunas partes, fuera "la voz sin voz".

No estamos ante "el fin de la historia". La historia ni ha terminado, ni puede enrumbarse, ni centrarse en criterios economicistas y mercantiles, que desfiguran y desnaturalizan la esencia de "lo social" de la economía y reducen "la modernización" nacional a la eficiencia productora del sector estatal. Cabe recordar aquí la sentencia evangélica que afirma que "no sólo de pan vive el hombre". Entonces, ¿qué es modernización?

\section{6. ¿Qué es modernización?}

Llegamos a la conclusión de que no es fácil dar una definición de la modernización, porque definir es poner límites, es decir, esto sí y esto no. Más bien llegamos a concluir que no estamos de acuerdo con algunas definiciones de modernización, por ser muy restringidas y limitadas; o tal vez que nos acercamos al significado de qué es modernización a través de lo que no es modernizacón.

Modernización no es catalogar el estándar de vida de un país en función de los crecimientos macroconómicos, cuyos promedios o per capitas esconden las mayores desigualdades y no especifican la naturaleza de los bienes y servicios producidos. Los_economistas se resisten a admitir que su ciencia social se reduzca a parámetros cuantitativos, porque entonces deja de ser ciencia, interpretación de los hechos y sus causas, y deja de ser social, qué seres humanos quedan beneficiados $y$ marginados. Los economistas sociales se resisten a admitir que la modernización se quiera restringir al sector y a la propiedad públicos y privados. Los sectores y las propiedades, públicos y privados, tienen una función social y se integran en el conjunto de servicios y órdenes sociales. La modernización y su derivada privatización tienen un fin mayor y una función social. Así, desde esta pers- pectiva del fin mayor y de su función social nos hemos avocado a analizar el proceso de privatización en El Salvador20.

La edad moderna no se inicia con un modelo triunfalista que desdeña los valores perennes de la solidaridad, la justicia, el progreso colectivo, reduciendo las relaciones sociales a operaciones de comprar y vender. El mundo dejaría de ser mundo para convertirse en un gran marketing. Aunque no sabemos cómo irán a evolucionar los hechos, algunos países del bloque ex socialista están dando un voto mayoritario a los partidos comunistas, nacionalistas, socialdemócratas, no tanto para volver hacia atrás cuanto para mostrar su rechazo al modelo de mercado y a la forma en que se les ha impuesto. Algunos partidos vuelven a sacar el viejo calificativo de capitalismo salvaje. Esta referencia, por cierto transitoria, porque no sabemos cómo evolucionará el próximo futuro de estos países, nos acerca a otro parámetro más idóneo para evaluar la modernización, "la satisfacción social". Si no hay satisfacción social, que es más que producción mercantil, no se le ha atinado a la modernización. Esto parece que despunta en el bloque ex socialista.

La satisfacción social fraterniza con el logotipo de Conpenhague: las sociedades prósperas son las que existen en función del ser humano. Con esta reflexión podemos aterrizar en nuestro país. Luego de tantos artículos sobre la modernización, que cierran con el gran titular, en primera página del 24 de diciembre: "Modernización del Estado es vital", resulta que es la Procuradora para la Defensa de los Derechos Humanos quien nos ubica más acertadamente en el centro de la modernización. He aquí algunos párafos de su mensaje de fin de año.

Las necesidades básicas de la mayoría de la población no están atendidas. Cincuenta y uno por ciento de los salvadoreños sufren de pobreza absoluta. 153 mil niños salvadoreños, menores de cinco años, son desnutridos y la mortalidad infantil asciende a 46 por mil. El 40 por ciento de la población no tiene acceso a los servicios de salud. Existe un déficit de $470 \mathrm{mil}$ viviendas. El 53 por ciento de los salvadoreños no tiene agua potable. El analfabetismo no disminuye y abarca al 29 por ciento de la población, y 379 mil niños no tienen acceso a la educación primaria (datos del Banco Mundial y PNUD). Estos indicadores presentan una si- 
tuación económica y social que significa violaciones sistemáticas a los derechos a un nivel de vida adecuado, a la alimentación, a la salud, a la vivienda, a la educación y al empleo. Este panorama es producto de un proceso acumulativo de pobreza respecto al cual históricamentc es responsable el Estado. El gobiemo de El Salvador ha asumido el compromiso ante el pueblo e internacionalmente de mejorar progresivamente los derechos económicos y sociales de la población y es de su responsabilidad elaborar y ejecutar políticas sociales realmente encaminadas a este objetivo.

Miles de salvadoreños verán ensombrecida la navidad al coincidir ésta con los despidos masivos en aplicación del Decreto 471. De igual manera, los derechos laborales de los trabajadores y trabajadoras de las maquilas se ven afectados y si el Estado no asume decididamente el cumplimiento de la legislación existente para preservar esos derechos... Esto obliga al Estado a legislar adecuadamente para que haya un régimen laboral justo y legal, donde el respeto a la dignidad del ser humano sea una norma fundamental.

Si del ámbito económico laboral pasamos al campo de la seguridad y aplicación de la ley, la modernización estatal presenta nuevas funciones.

En El Salvador hay un grave problema de delincuencia común que afecta a la población. La delincuencia afecta crecientemente la seguridad de los ciudadanos. La manera más directa para que la delincuencia disminuya y se controle es aplicando la ley de manera ejemplar. Sin excepciones. Sancionando a todos los delincuentes. Incluyendo a quienes teniendo el deber de hacer cumplir la ley, la violan. Esta sanción daría un mensaje a la población de lucha contra la impunidad. El problema no es teórico, es práctico. Aplicar la ley y la sanción sin excepciones de ninguna naturaleza. El aumento de la delincuencia es directamente proporcional al grado de impunidad y a la situación de pobreza... Es innegable que pese a los valiosos esfuerzos del Organo Judicial, la impunidad se sigue concentrando en los procesos administrativos policiales y judiciales. No se sanciona con la eficiencia y la celeridad debida a quienes cometen delitos que son violaciones a los derechos humanos o a quienes simplemente delinquen, quedando muchos de ellos sin sanción. Estas son, entre otras, la causas principales de la violencia que afecta a los ciudadanos y de los graves problemas de seguridad pública que vive el país.

La Procuradora para la Defensa de los Derechos Humanos hace referencia también al hecho de que el Estado pueda violar ciertas normas constituciones, transgrediendo la ley, con lo cual los ciudadanos se sienten totalmente desprotegidos. Cita dos casos bastante conocidos: la modificación del reglamento de la inspectoría general de la Policía Nacional Civil, parcialmente corregida, y el Decreto 471, parcialmente inconstitucional, que afecta el derecho al trabajo de 15 mil salvadoreños. Hubiera sido preferible que la cadena nacional impuesta a los medios de comunicación al final del año se hubiera dedicado a este mensaje de la Procuradora para la Defensa de los Derechos Humanos. Supliendo las preferencias gubernamentales y en el supuesto de que poca gente leyó este mensaje el 29 de diciembre, lerminamos citando un último párrafo.

La paz social, el Estado de derecho, la modernización económica, la lucha contra la impuni-

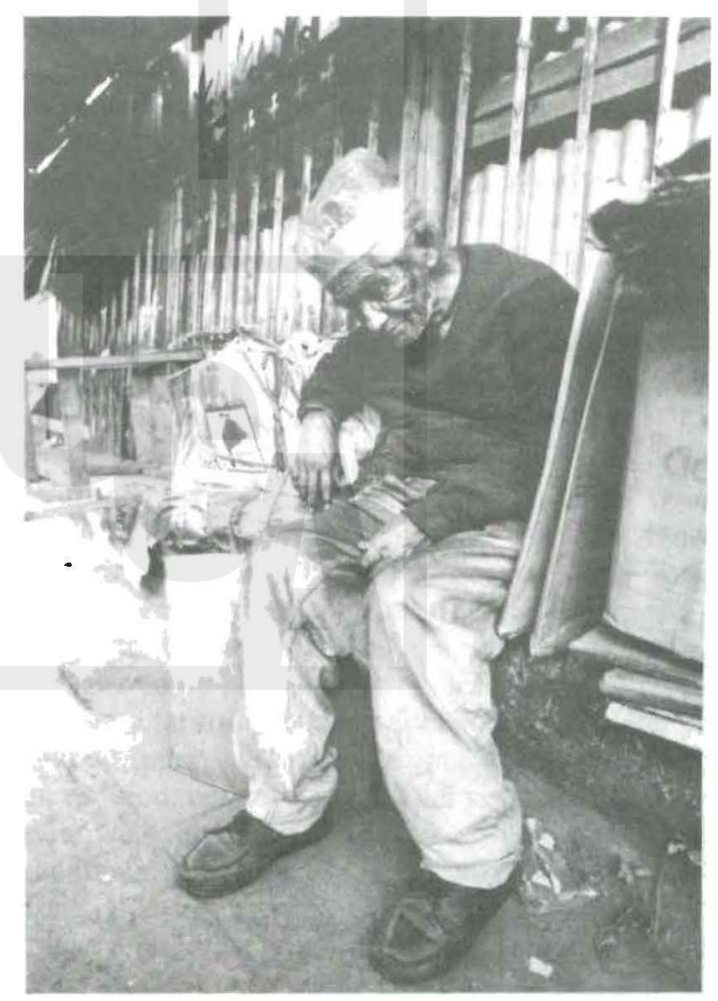


dad y la inseguridad pública, la defensa del principio de la legalidad y la protección de los derechos humanos, son componentes interrelacionados de la gobernabilidad y la irreversibilidad de los acuerdos de paz. La paz es una aspiración que los salvadoreños hemos buscado a lo largo de nuestra historia. Luego del conflicto armado hemos sentado las bases para alcanzarla con la cooperación de la comunidad internacional. Ahora nuestra responsabilidad es darle sostenibilidad. Para ello las instituciones creadas o reformadas por los acuerdos de paz deben cumplir cabalmente sus funciones constitucionales para que la vida democrática sea una realidad21.

\section{Notas}

1. Victoria Marina Velázquez de Avilés, Procuradora para la Defensa de los Derechos Humanos. La Prensa Gráfica, 29 de diciembre de 1995.

2. Varios. El neoliberalismo en cuestión. España, Sal Terrae, 1993. Seminario organizado por Cristianisme i Justicia. Barcelona.

3. Varios. Etica, economía, política y pobreza. Colombia, Fundación Simón Bolívar, 1995. Seminario organizado por la Fundación Konrad Adenauer y CIEDLA.

4. Luis de Sebastián, El neoliberalismo en cuestión, op. cit., pp. 27-28.

5. Hans Jurgen Rosner, El neoliberalismo en cuestión, pp. 70-71.

6. Ibidem, p. 68.

7. Jacob Richard, Política social en la economía social de mercado. Contribuciones 3/92, pp. 86-87.

8. F. A. von Hayek, Etica, economía, política y pobreza, p. 87.

9. Ibidem, pp. 87-88.

10. Ibidem, p. 88.

11. H. Jurgen Rosner, op. cil., pp. 72-75.

12. Luis de Sebastián, op. cit., pp 28-29.

13. H. Jurgen Rosner, op. cit., p. 75,

14. Ibidem, p. 77.

15. Jacob Richard, op. cit., pp 91-92.

16. Eduardo Rojo, El neoliberalismo en cuestión, op. cir., pp 16-17.

17. Luis de Sebastián, op. cit., p. 29.

18. J. M. Mardones, op. cit., p. 231.

19. R. Damasceno Assis, op. cit., p. 89.

20. M. I. Peñate, Y. Y. Bonilla, S. A. Vázquez, "El proceso de privatización en El Salvador: el caso de ANTEL, CEL". Universidad Centroamericana “José Simeón Cañas", Tesis de grado, enero de 1996.

21. Ver la nota 1. 